\title{
Hypertensive Diabetic Patients. Guidelines for Conduct and Their Difficulties
}

\author{
Weimar K. S. Barroso, Paulo César B. V. Jardim, Thiago S. V. Jardim, Cláudio T. S. Souza, \\ Alessandro L. A. Magalhães, Fuad M. Ibrahim, Priscila V. O . Couto, Andrea Silveira, \\ Estelamaris T. Monego \\ Goiânia, GO - Brazil
}

\begin{abstract}
Objective - To assess the effect of blood pressure (BP) control and other cardiovascular risk factors in patients with diabetes mellitus in a referral service for the treatment of hypertension.
\end{abstract}

Methods - A retrospective study where diabetic patients (at least 2 fasting glucose levels above $126 \mathrm{mg} / \mathrm{dL}$, use of hypoglycemic agents or insulin, or both of these) were included. They were evaluated at the first appointment (MI) and at the last appointment (M2), regarding blood pressure, body mass index (BMI), use of hypertensive drugs, glycemia, total cholesterol (TC), creatinine, and potassium.

Results - Of 1,032 patients studied, 146 patients with a mean age of 61.6 years had diabetes, and 27 were men (18.5\%). Mean follow-up was 5.5 years. BP values were $161.6 \times 99.9 \mathrm{mmHg}$ in $\mathrm{Ml}$ and $146.3 \times 89.5 \mathrm{mmHg}$ in M2. In M1, 10.4\% of the patients did not use medications, $50.6 \%$ used just 1 drug, 30.8\% used 2 drugs, and $8.2 \%$ used 3 or more drugs. In M2, these values were 10.9\%, 39\%, 39.7\%, and $10.4 \%$, respectively. Diuretics were the most commonly used medication, whereas angiotensin-converting enzyme inhibitors (ACE inhibitors) were those drugs which presented greater increase when comparing M1 to M2 (24.6\% and $41.7 \%$, respectively). Only $17,1 \%$ reached the recommended goal $(B P<130 \times 85 \mathrm{mmhg})$. The other cardiovascular risk factors did not change significantly.

Conclusion - Our data reinforce the necessity of a more aggressive approach in the treatment of these patients, despite the social and economic difficulties in adhering to treatment.

Key words: hypertension, diabetes, treatment

Hypertension League (LHA) - Faculdades de Medicina, Enfermagem e Nutrição Hospital das Clínicas - UFG.

Mailing address: Paulo César B. V. Jardim - Rua 115-F, nº 135 - Setor Sul - 74085-300 Goiânia, GO, Brazil - Email: fvjardim@terra.com.br
It has been proved that blood hypertension treatment is followed by an important decrease in cardiovascular events, in the incidence of stroke, acute myocardial infarction, heart failure, as well as a delay in the progression of renal failure.

Despite all these benefits, the number of hypertensive patients who indeed reach the goal proposed by several guidelines ${ }^{1-3}$ is still very low.

The reasons for these frustrating results, even in the patients who adhere to treatment, vary from the difficulties in following the guidelines related to lifestyle, to the impossibility of buying the medications prescribed.

We must take into account those health professionals who, many times, have neglected the recommendations about the importance of treatment. Some "apathy" exists in the medical community concerning rigorous blood pressure control and the concomitant risk factors ${ }^{4}$.

Currently, the goal for hypertensive patients is that blood pressure levels should be $<140$ x $90 \mathrm{mmHg}$.

For special groups (patients with cardiovascular diseases, renal failure, or diabetes), the goals are more rigorous and blood pressure must be below $130 \times 85 \mathrm{mmHg}^{1-3,5-7}$, due to the high risk of complications.

The prevalence of diabetes mellitus type II in the Western world is increasing. The risk of cerebrovascular diseases in these patients is greatly increased, and it is estimated that 4 in each 5 patients with diabetes mellitus type II will die due to cardiovascular diseases. Furthermore, the risk of death from cardiovascular causes in diabetic patients after a 12-year-follow-up is approximately 3 times greater when compared with the risk in nondiabetic patients.

These individuals, even with controlled risk factors and blood pressure, still have increased morbidity ${ }^{5-8}$.

These facts reinforce the necessity of rigorous control of risk factors and of blood pressure in this specific group.

Data from the HOT Study ${ }^{9}$ demonstrate benefits in the reduction of blood pressure for values lower than $130 \mathrm{mmHg}$ for systolic blood pressure and $85 \mathrm{mmHg}$ for diastolic blood 
pressure. These benefits were evident in the study, causing a reduction both in microvascular and macrovascular disease.

In this study, the subgroup of diabetic patients comprised those who received greater benefits from the rigorous control of pressure levels.

To adequately control hypertension, the use of many antihypertensive medications is usually necessary ${ }^{5-7}$. This observation was demonstrated in patients with diabetes mellitus in the UK Prospective Diabetes Study Group (UKPDS ${ }^{10}$ study, where an increased number of antihypertensive drugs were used during the 9-year follow-up.

We observed at the end of the study that, in the group of randomized patients for rigorous control of blood pressure, $29 \%$ used 3 or more hypotensive drugs, whereas in the group with less strict control of blood pressure, only $11 \%$ used this number of medications.

Clinical and experimental evidence have demonstrated that angiotensin-converting enzyme inhibitors (ACE inhibitors) are beneficial in the treatment of hypertensive diabetics. These benefits are evident regarding cardiovascular diseases in general, and even more evident concerning renal protection ${ }^{1-3,5-7,11-13}$.

Recently, benefits of these medications were demonstrated even in normotensive diabetics, with a significant reduction not only in diabetic morbidity but also in the incidence of new-onset diabetes ${ }^{14-16}$.

Therefore, angiotensin-converting enzyme inhibitors may be considered first-line agents in the treatment of hypertension in diabetic patients, alone or associated with other hypotensive agents.

The Hypertension League of the UFG is a referral center for the treatment of hypertension and cardiovascular risk factors, formed by a multidisciplinary staff with doctors, nurses, nutritionists, and psychologists. Appointments are customized and, when necessary, the treatment approach is discussed with the staff members.

In the approach for the hypertensive patient, the nonmedicamentous treatment is emphasized at each appointment.

The League also promotes educational activities, quarterly, when several themes related to cardiovascular diseases and their risk factors are presented by health professionals and later discussed with participants.

The adherence rate to the League is excellent, greater than $65 \%$ in a 10 -year follow-up.

These particularities assure a very satisfactory level of success in the treatment of hypertensive patients, and we hope that the same level of efficiency is reached in special groups.

The objective of our study was to assess the effective control of blood pressure and other risk factors in hypertensive diabetics in a referral center for the treatment of hypertension.

\section{Methods}

From January to March 2000, we assessed retrospectively the charts of patients enrolled in the Hypertension
League from UFG, and we selected for the study all diabetic patients under treatment.

Criteria used for diagnosis of diabetes were (1) individuals with 2 or more fasting glucose levels above $126 \mathrm{mg} /$ $\mathrm{dL}$, (2) those who used oral hypoglycemic medication or insulin, (3) both of these.

Patient data were collected during the following 2 periods: $\mathrm{M} 1$ (corresponding to the 1st medical appointment), and M2 (corresponding to the last medical appointment at the League); the interval between these 2 periods varied from one to 10 years $(5.5 \pm 2.6)$. We evaluated the following variables: age and sex; weight and height; body mass index (BMI); systolic blood pressure (SBP); diastolic blood pressure (DBP); hypotensive medication used, its amount and variations; laboratory tests, glycemia, total cholesterol, creatinine, and potassium.

To analyze systolic and diastolic blood pressure, we considered the highest value measured with the patient seated.

Regarding the treatment, we evaluated the use of antihypertensive medication, associated risk factors, and changes in lifestyle.

Hypotensive medications were assessed regarding the group (calcium antagonists (CA); beta-blockers (BB); diuretics (D); angiotensin-converting enzyme inhibitors (ACE inhibitors); angiotensin II receptor antagonists, and central vasodilators that have a central action (VD). We evaluated their isolated or associated use and the number of associations when it was present.

Because of the small number of patients using angiotensin II receptors antagonists, we considered these patients and those patients using ACE inhibitors as the same group.

We excluded the charts that did not fulfill the criteria for analysis.

The League uses standardized charts where, besides objective clinical information, data concerning cardiovascular risk factors, life style, use and dosage of medications are systematically collected.

We assess weight and height to calculate body mass index. All patients had their weight and height measured in a mechanical balance, adequately calibrated.

Pressure is assessed systematically by a trained medical staff, using a calibrated mercury column device, and 2 measures are obtained in each of the positions, seated and lying. Technical recommendations used are those advised by $\mathrm{WHO} / \mathrm{SBC} / \mathrm{JNC}^{1-3}$.

Laboratory tests were performed at the laboratory of the Hospital das Clínicas of UFG.

We used the Wilcoxon test to analyze the variations of blood pressure and Fischer's exact test to compare qualitative variables between the groups (number of drugs and types of drugs used). We used as a critical value, significance at $5 \%$.

\section{Results}

Of 1,032 patients, $156(15.1 \%)$ diabetic patients were selected. Ten patients were excluded because they did not fulfill the analysis criteria. 
We studied 146 hypertensive individuals with type II diabetes mellitus who represented $93.5 \%$ of all the diabetics from the center. Mean age was 61.6 \pm 10.4 (32 to 90) years; 119 were women $(81.5 \%)$. The analyzed period was $5.5 \pm 2.6$ (1 to 10) years.

In M1, $10.4 \%$ of the patients did not use medications, $50.6 \%$ used 1 medication, and $8.2 \%$ used 3 or more medications. In M2, these percentages were $10.9 \%, 39 \%, 39.7 \%$, and $10.4 \%$, respectively (fig. 1 ).

Diuretics were the most commonly used antihypertensive medication ( $47.9 \%$ in M1 and $50.6 \%$ in M2). Angiotensin-converting enzyme inhibitors were used in $24.6 \%$ at the first appointment, and $41.7 \%$ at the last. Calcium channel antagonists, beta-blockers, and central vasodilators were used, respectively, in $28.7 \%, 13 \%$, and $21.2 \%$ in M1 and $30.1 \%, 15.7 \%$ and $12.3 \%$ in $\mathrm{M} 2$ (fig. 2).

Regarding the pressure levels, we observed a 15.3 $\mathrm{mmHg}$ decrease in SBP (from $161.6 \mathrm{mmHg}$ in M1 to 146.3 mmHg in M2), and of $10.4 \mathrm{mmHg}$ in DBP (from $99.9 \mathrm{mmHg}$ in M1 to $89.5 \mathrm{mmHg}$ in M2), both with statistical significance (fig. 3). However, only $17.1 \%$ of the patients reached the advised goal for diabetics (blood pressure $<130$ x $85 \mathrm{mmHg}$ ) and only $41.7 \%$ of the patients had blood pressure lower than 140 $\mathrm{x} 90 \mathrm{mmHgin} \mathrm{M} 2$.

Body mass index values did not change between the first and the last evaluation $\left(29.5\right.$ and $29.3 \mathrm{~kg} / \mathrm{m}^{2}$, respectively).

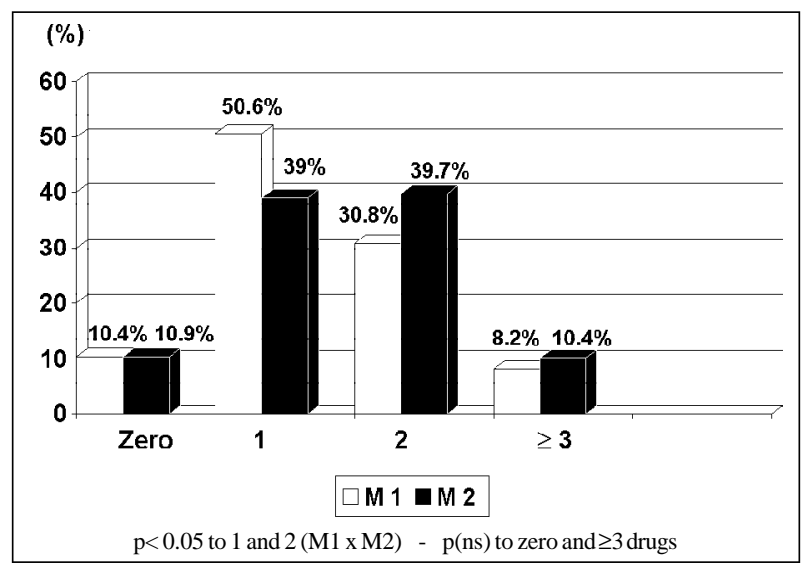

Fig. 1 - Number of antihypertensive used at first (M1) and last appointment (M2)

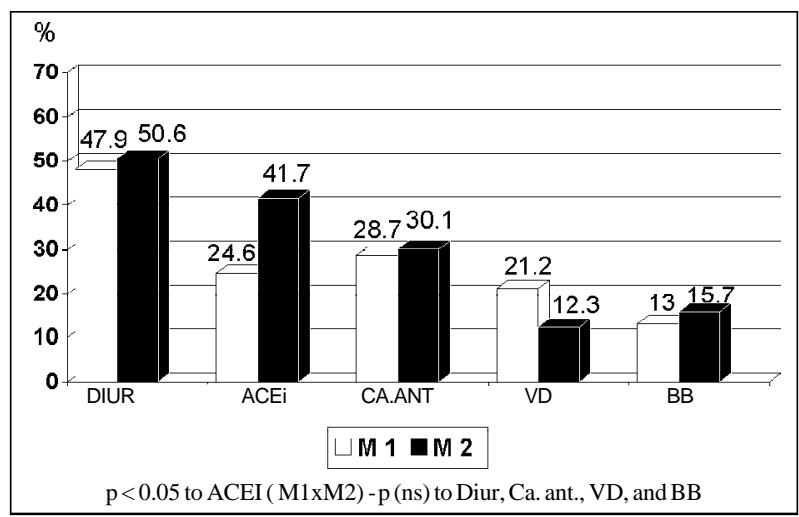

Fig. 2 - Antihypertensive used at first (M1) and last appointment (M2).
Regarding laboratory blood tests, we did not observe significant differences between the beginning and the end of the observation (tab. I).

Oral hypoglycemic medications were used by only $34.9 \%$ of the diabetics in M2 and insulin was used by $4.7 \%$ of patients, in contrast with the greater number of patients with glycemia values above that recommended for good metabolic control.

\section{Discussion}

The association between blood hypertension, diabetes mellitus, and dyslipidemia in the same individual is frequent, characterizing insulin resistance syndrome, which considerably increases the risk for atherosclerotic disease.

We know that the presence of diabetes increases the individual risk for coronary artery disease so that it corresponds with the occurrence of 1 previous myocardial infarction, and that the association of a previous myocardial infarction with diabetes mellitus increases the chance of a new infarction to $45 \%$ in 7 years ${ }^{5,17}$.

Rigorous control of blood pressure, glycemia, and lipids significantly reduces cardiovascular events and decreases the incidence and progression of renal impairment, retinal lesion, and peripheral vascular disease ${ }^{5,18}$.

Even with awareness of these facts, one of the greatest challenges in handling these groups of individuals is reaching the goals proposed for achieving these benefits ${ }^{5-8}$.

In our patients, significant and important decreases occurred both in the level of systolic blood pressure $(-15.3$ $\mathrm{mmHg})$ and in the diastolic blood pressure $(-10.4 \mathrm{mmHg})$.

However, in analyzing the goals proposed, we observed that only $41.7 \%$ of the individuals had values lower

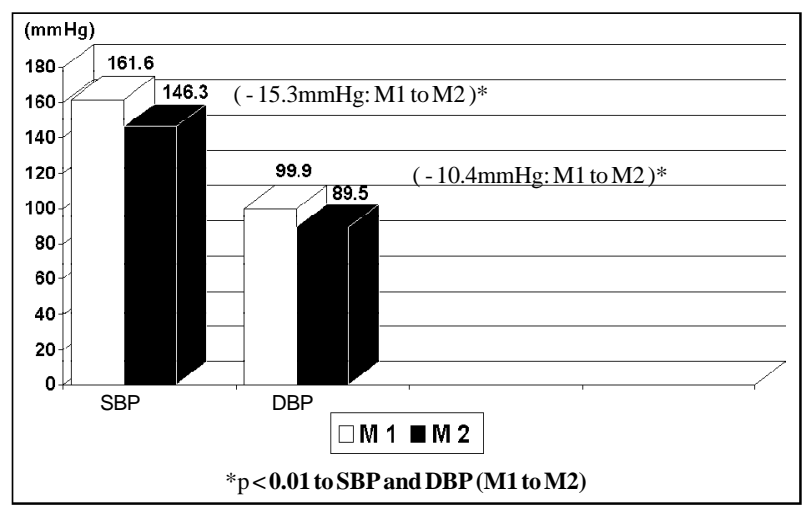

Fig. 3 - Blood Pressure at the first (M1) and last appointment (M2)

\begin{tabular}{|lccccc|}
\hline \multicolumn{6}{|c|}{ Table I - Laboratory Findings at M1 and M2 } \\
\hline Variable & & M1 & M2 & Difference & $\mathrm{p}$ \\
\hline Glycemia & $(\mathrm{mg} / \mathrm{dl})$ & 145.7 & 153.7 & +8 & $\mathrm{~ns}$ \\
Cholesterol $(\mathrm{mg} / \mathrm{dl})$ & 218.8 & 221.8 & +3 & $\mathrm{n} \mathrm{s}$ \\
Creatinine & $(\mathrm{mg} / \mathrm{dl})$ & 0.94 & 0.85 & -0.09 & $\mathrm{n} \mathrm{s}$ \\
Potassium & $(\mathrm{Mmol} / \mathrm{l})$ & 4.2 & 4.8 & +0.6 & $\mathrm{n} \mathrm{s}$ \\
\hline
\end{tabular}


than $140 \times 90 \mathrm{mmHg}$ (which is the goal for the general population), and only $17.1 \%$ of them had values lower than $130 \mathrm{x}$ $85 \mathrm{mmHg}$ (the goal for diabetic patients).

In the UKPDS ${ }^{10}$, the patients who maintained a rigorous control of blood pressure $(144 \times 82 \mathrm{mmHg})$ compared with the control group with a less rigorous control were using a larger quantity of antihypertensive medications (29\% of the patients from the rigorous control group used 3 or more medications, and only $11 \%$ from the less controlled group used this quantity of medication).

Concerning our sample, we observed a decrease from $50.6 \%$ to $39 \%$ of patients using just 1 antihypertensive medication. Consequently, an increase from $30.8 \%$ to $39.7 \%$ of individuals using 2 associated medications occurred, and the use of 3 or more medications increased from $8.2 \%$ to $10.4 \%$.

The use of associated medications ( 2 or 3 ) is still low although it has increased to $50.1 \%$, and it could certainly favor a better control of the blood pressure if a greater amount of medication was used.

Our data, like that reported in the literature, clearly demonstrate the necessity of the association of antihypertensive medication for a better control of blood pressure for the reduction of the cardiovascular risk in this special group.

Diuretics were the most commonly used antihypertensive medication both in the beginning (in $47.9 \%$ of the patients) and in the end (in 50.6\%).

These medications, despite being able to change the metabolic profile in more increased doses, do not seem to affect it significantly when used in low doses $(6.25 \mathrm{mg}$ to $25 \mathrm{mg} /$ day of hydrochlorothiazide or similar drugs $)^{15}$.

Additionally, these medications have already proved their efficacy in the reduction of cardiovascular events, in hypertensive patients, and especially in hypertensive diabetic patients over 60 years old ${ }^{19}$.

For this reason and because of the low cost, this group of medications is one of the first choices in the treatment of all hypertensive patients, including the diabetic patient. They are also an excellent option as a first choice in association with antihypertensive medications.

The use of angiotensin-converting enzyme inhibitors increased from $24.6 \%$ to $41.7 \%$ of the patients, representing an increase of $69.5 \%$ related to the beginning of the study. However, this increase was less than that desired due to all the benefits that this group of medications provides to this particular population. The high cost of this group of medications may be a limiting factor in its indication, but we should point out the importance of its use, which in the mediumand long-term follow-up would be clearly beneficial in terms of cost versus benefit.

Data from the HOPE Trial demonstrate benefits with the use of angiotensin-converting enzyme inhibitors even in normotensive diabetic patients (mean blood pressure, when included in the study, was $133 \times 76 \mathrm{mmHg}$ in the ramipril group); they also had significant reductions in complications related to diabetes mellitus ${ }^{14}$. Furthermore, several studies ${ }^{10,11,14}$ clearly demonstrate the capacity of protection of these drugs both for microvascular and macrovascular diseases, and in some clinical reports, a lower incidence of diabetes mellitus was verified in hypertensive patients using this class of drugs ${ }^{16,20}$.

Recent studies ${ }^{21,22}$ have also demonstrated the beneficial action of angiotensin II receptor antagonists in preventing microalbuminuria, and in hypertensive diabetic patients significantly delaying the progression of significant proteinuria (> $300 \mathrm{mg} /$ day) and end-stage renal disease (patient needing dialyses and/or renal transplantation, or having serum creatinine $\geq 6 \mathrm{mg} / \mathrm{dL}$ ).

Data from the RENAAL study ${ }^{23}$ show similar results to the previous one and demonstrate a decrease in the first hospital admission due to heart failure in the group treated with angiotensin II receptor antagonists.

Maintenance of body mass index above the desirable levels due to lack of weight control is another aspect to be considered. This fact is accentuated, especially in this group, where the maintenance of normal weight is of utmost importance both for the control of blood pressure and plasma glycemia. Control of body weight is one of the most effective and important nonpharmacologic measures in the treatment $^{24}$, and weight control is one of the greatest challenges of these days especially in high-risk populations.

Regarding the metabolic profile, our study group did not have significant variations during the treatment.

Plasma cholesterol levels, despite being within the maximum safety limits, should have also been taken into account more carefully due to the peculiarity of high risk of the group ${ }^{25}$.

Recent recommendations suggest that treatment with statin drugs should be started in diabetics who, in spite of nonpharmacological treatment, still have LDL levels above $100 \mathrm{mg} / \mathrm{dL}^{26}$.

The persistence of increased plasma glycemia above desired levels caught our attention because only $34.9 \%$ and $4.7 \%$ of the individuals were using oral hypoglycemic agents and insulin, respectively, at the end of the study period. Because of the importance of maintaining fasting glucose and glycosylated hemoglobin under strict control ${ }^{27}$, the need for a more aggressive and less observational approach is reinforced also for this variable.

We concluded that our data reflect, in general, that a tendency exists to more carefully approach the patient with hypertension associated with diabetes mellitus. There is in fact an increase in the use of associated medication to control the pressure and a clear recommendation towards the more frequent use of angiotensin-converting enzyme inhibitors in diabetic patients.

However, we were surprised by the lower number of individuals with blood pressure adequately controlled, who had values of $\mathrm{BP}<140$ x $90 \mathrm{mmHg}$, or even $\mathrm{BP}<130 \mathrm{x}$ $85 \mathrm{mmHg}$, as recommended for diabetic patients. The proportion of patients using 3 or more antihypertensive medications $(10.4 \%)$ could facilitate reaching the goals proposed in the control of pressure.

Weight control and careful control of cholesterol levels and glycemia are still inadequate, especially if we take 
into account that it is at a referral center where the professionals are aware of its importance.

These data are an alert and call attention to the necessity of changing the conduct to a more aggressive approach with these patients. Thus, we will have glycemia levels and other metabolic parameters within those recommended; likewise, blood pressure will be closer to the ideal levels for effective decreases in cardiovascular risks in this population.
It is important to remember that regardless of the economic difficulties and limitations consequent to the use of medications that are very effective for treating several conditions in patients with this syndrome, the benefits secondary to the decrease in morbidity and mortality due to adequate treatment are evident, both economically and regarding quality of life. Therefore, it is worth implementing this treatment in all services handling hypertensive diabetic patients.

\section{References}

1. Joint National Committee on Prevention, Detection, Evaluation, and Treatment of High Blood Pressure. The sixth report of the Joint National Committee on Prevention, Detection, Evaluation, and Treatment of High Blood Pressure. Arch Intern Med 1997; 349: 454-57.

2. 1999 World Health Organization - International Society of Hypertension Guidelines for the management of Hypertension. J Hypertens 1999; 17: 151-183.

3. III Consenso Brasileiro de Hipertensão Arterial. HiperAtivo 1999; 6: 67-106.

4. Berlowitz DZ, Ash AS, Hickey EC, et al. Inadequate management of blood pressure in hypertensive population. N Engl J Med 1998; 339: 1957-63.

5. Arauz-Pacheco C, Parrot M, Raskin P. The treatment of hypertension in adult patient with diabetes. Diabetes Care 2002; 25(suppl. I): 134-47.

6. Basta M, Bakris G. Escolhas e metas no tratamento do paciente diabético hipertenso. Curr Hypertens Reports Brasil 2001; 1: 286-90.

7. Deedwania PC. Hypertension and diabetes. New therapeutic options. Arch Intern Med 2000; 160: 1585-94.

8. Sowers JR. Diabetes and hypertension. Curr Concepts in Hypertension 1999; 3:2-4.

9. Hansson L, Zanchetti A, Carruthers SG, et al. Effects of intensive blood-pressure lowering and low-dose aspirin in patients with hypertension: principal results of the Hypertension Optimal Treatment (HOT) randomised trial. Lancet 1998; 351: 1755-62

10. UK prospective diabetes study group. Tight blood pressure control and risk of macrovascular and microvascular complications in type 2 diabetes: UKPDS 38 Br Med J 1998; 317: 703-13.

11. Maschio G, Albert D, Janin G, et al. Effect of the angiotensin-converting-enzyme inhibitor benazepril on the progression of chronic renal insufficiency. N Engl J Med 1996; 334: 939-45.

12. Estacio R, Jeffers BW, HiattWR, Biggerstaff SL, Gifford N, Schirier RW. The effect of nisoldipine as compared with enalapril on cardiovascular outcomes in patients with non-insulin-dependent diabetes and hypertension. N Engl J Med 1998; 338: 645-52.

13. Bakris GL, Williams M, Dworkin L, et al. Preserving renal function in adults with hypertension and diabetes: a consensus approach. National Kidney Fundation Hypertension and Diabetes Executive Committees Working Group. Am J Kidney Dis 2000; 36: 646-61.

14. Yusuf S, Sleight P, Pogue J, Bosch J, Davies R, Dagenais G. The heart outcomes prevention evaluation study investigators: effects of an angiotensin-converting-enzyme inhibitor, ramipril, on cardiovascular events in high-risk patients. N Engl J Med 2000; 342: 145-53.
15. Gress TW, Nieto J, Shahar E, Wofford M, Brancati F. Hypertension and antihypertensive therapy as risk factors for type 2 diabetes mellitus. N Engl J Med 2000; 342: 905-12.

16. Niskanen L, Hedner T, Hansson L, Lanke J, Niklason A, and for the CAPPP study group. Reduced cardiovascular morbidity and mortality in hypertensive diabetic patients on first-line therapy with an ACE inhibitor compared with a diuretic/beta-blocker-bases treatment regimen: a subanalysis of the captopril prevention project. Diabetes 2001; 24(suppl. XII): 2091-96.

17. Haffner SM, Lehto S, Ronnemaa T, et al. Mortality from coronary heart disease in subjects with type 2 diabetes and in nondiabetic subjects with and without prior myocardial infarction. N Engl J Med 1998; 339: 229-34.

18. Prisant LM, Louard RJ. Controversies surrounding the treatment of the hypertensive patient with diabetes. Curr Hypertens Rep 1999; 1: 512-20.

19. Curb JD, Pressel SL, Cutler JA, et al. Effect of diuretic based antihypertensive treatment on cardiovascular disease risk in older diabetic patients with isolated systolic hypertension. Systolic Hypertension in the Elderly Program Cooperative Research Group. JAMA 1996; 276: 1886-92.

20. Hansson L, Lindholm LH, Niskanen L, et al. Effect of angiotensin-convertingenzyme inhibition compared with conventional therapy on cardiovascular morbidity and mortality in hypertension: The Captopril Prevention Project (CAPPP) Randomised Trial. Lancet 1999; 353: 611-6.

21. Lewis EJ, Hunsicker LG, Clarke WR, et al. Renoprotective effects of the angiotensin-receptor antagonist irbesartan in patients with nephropathy due to type 2 diabetes. N Engl J Med 2001; 345: 851-60.

22. Parving HH, Lehnert H, Brochner-Mortensen J, et al. The effects of irbesartan on the development of diabetic nephropathy in patients with type 2 diabetes. NEngl J Med 2001; 345: 870-8.

23. Brenner BM, Cooper ME, Zeeuw D, et al. Effects of losartan on renal and cardiovascular outcomes in patients with type 2 diabetes and nephropathy. $\mathrm{N}$ Engl J Med 2001; 345: 861-9.

24. The Trials of Hypertension Prevention Collaborative Research Group. The effects of nonpharmacologic interventions on blood pressure of persons with high normal levels. JAMA 1992; 267: 1213-20.

25. $2^{\circ}$ Consenso Brasileiro sobre Dislipidemias - Detecção - Avaliação - Tratamento. Arq Bras Cardiol 1996; 67 (supl.): 1 - 16.

26. Maron DJ, Fazio S, Linton MF. Current perspectives on statins. Circulation 2000; 101: 207-13.

27. Grundy SM, Benjamin IJ, Burke GL, et al. Diabetes and cardiovascular disease. A statement for healthcare professionals from the American Heart Association. Circulation 1999; 100: 1134-46. 